\title{
Effect of Different Sound Frequencies on the Growth and Antibiotic Susceptibility of Escherichia coli
}

\author{
Souvik Banerjee*, Abhishek Goswami, Ananya Datta, Anish Pyne, \\ Anjoom Nikhat and Bodhisattwa Ghosh \\ Department of Microbiology (St. Xavier's College, Kolkata), India \\ *Corresponding author
}

\section{A B S T R A C T}

Keywords

Antibiotic

susceptibility, $E$.

coli, Sound

frequencies

Article Info

Accepted:

16 February 2018

Available Online:

10 March 2018
Effect of three types of sound frequencies falling within the audible range $(20 \mathrm{~Hz}-20$ $\mathrm{KHz}$ ), on bacterial growth and the antibiotic susceptibility was investigated. The bacteria used as the test organism (E. coli) was found to register better (17.5-25.67\%) growth at a frequency below $1 \mathrm{KHz}(432 \mathrm{~Hz})$, but surprisingly were witnessed to register an extremely poor $(83.45-86.72 \%)$ growth at a frequency above $1 \mathrm{KHz}(4 \mathrm{KHz})$ under the influence of distinctive sound frequencies. Sound treatment was also found to affect the antibiotic susceptibility, as our test organism was shown to exhibit a greater (11.14-13.23\%) antibiotic susceptibility under the influence of a frequency below $1 \mathrm{KHz}(432 \mathrm{~Hz})$, but again was shown to exhibit a lower (5.67-6.23\%) antibiotic susceptibility under the influence of a frequency above $1 \mathrm{KHz}(4 \mathrm{KHz})$. Intracellular concentration of cations (calcium and potassium) and protein content of the music treated cultures was also significantly different than the untreated control. The audible sound employed in this study was able to affect growth and antibiotic susceptibility of our test organism.

\section{Introduction}

Sound is a repeated pressure wave which travels through matter. Whether sound and biological cells can interact, whether sound can be exploited as a physical signal for intercellular communication, whether and how cells sense and respond to sound of varying frequency, remains interesting challenges to be explored.

When sound patterns are combined in a definite way, it translates into music. Not much research has been done on effect of audible sound (whether in form of music or otherwise) on microorganisms. Though research in this field has initiated and few reports describing effect of audible sound on microbes have appeared, much remains to be investigated. Largely the study regarding audible sound has revolved around how sound is produced, absorbed, reflected, and transmitted by different objects.

Not much attention has been paid to biological effects induced by audible sound and the underlying mechanism(s). The present study aimed at investigating effect of three kinds of sound frequencies on microbial growth and antibiotic susceptibility. 


\section{Materials and Methods}

\section{Test organism}

The organism used for this study was Escherichia coli, the common bacteria of our small intestine which otherwise plays an important role in the human digestive system.

\section{Experimental procedure}

The growth medium used in the experiment was Nutrient Agar, an artificial source necessary for providing the essential nutrients to enhance the bacterial growth in laboratory conditions. This was streaked over six petri dishes which were then inoculated with active culture of the test organism. Two specific sound frequencies were selected and were delivered over the mobile phones which were connected with the earphones. The earphones were adhered over the top of the petri dishes such that the inoculated organisms suffer the effect of the necessary frequencies. The six petri dishes were separated two sets (each one comprising three plates), and were used separately for the study of bacterial growth and antibiotic susceptibility. The set of plates used for studying the antibiotic susceptibility (by Kirby Baeur Method/Disk Diffusion Method) were affected with Tetracycline, so as to observe the necessary zones of inhibition. In each of the two sets, one plate was used as the control (where no sound frequency was used), the other two being under the influence of respective sound frequencies. These plates were then kept inside the BOD incubator overnight for 24 hours so as to allow the proper growth of our test organism. The incubator was covered with multiple layers of cloth and paper was used to cover the lid. This was done to prevent any possible leakage of sound from the chamber, and also to avoid any possible interference from external sound. The intensity of the sound played were also taken care of such that it has no negative impact upon the growth of the test organism.

\section{Results and Discussion}

\section{Effect of sound on bacterial growth}

The first set of petri dishes used for studying the bacterial growth, when taken out from the incubator after 24 hours of allowed incubation period, certain interesting colony characteristics were studied. The Control plate which was completely unaffected from any kind of sound interference was shown to have 39 bacterial colonies. Contrary to this, the plate exposed to a frequency of $432 \mathrm{~Hz}$, was shown to have 46 colonies, clearly stating that under the influence of sound the bacterial growth has certainly increased, by a margin of $17.54 \%$. Subsequent repetition of the experiment showed that this increase of the bacterial growth corresponding to the increase in sound frequency continues till $1 \mathrm{KHz}$. The reason behind this lies in the fact that, till 1 $\mathrm{KHz}$, as we keep on increasing the sound frequency, the nucleic acid synthesis inside the bacterial cell increases, which justifies the rise in bacterial growth.

The third plate exposed to a frequency of 4 $\mathrm{KHz}$ were witnessed to show an extremely scanty growth, exhibiting only 6 colonies, which once again clearly marked the decrease in the bacterial growth with subsequent increase of sound frequencies above $1 \mathrm{KHz}$, by a huge margin of almost $84 \%$. As studied, there may be two possible reasons behind this consistent decrease of bacterial growth corresponding to the increase in sound frequency above $1 \mathrm{KHz}$. These can be illustrated as follows:-

The increase in sound frequency above $1 \mathrm{KHz}$ leads to the production of toxic chemically reactive chemical species which are known as Reactive Oxygen Species (ROS). 


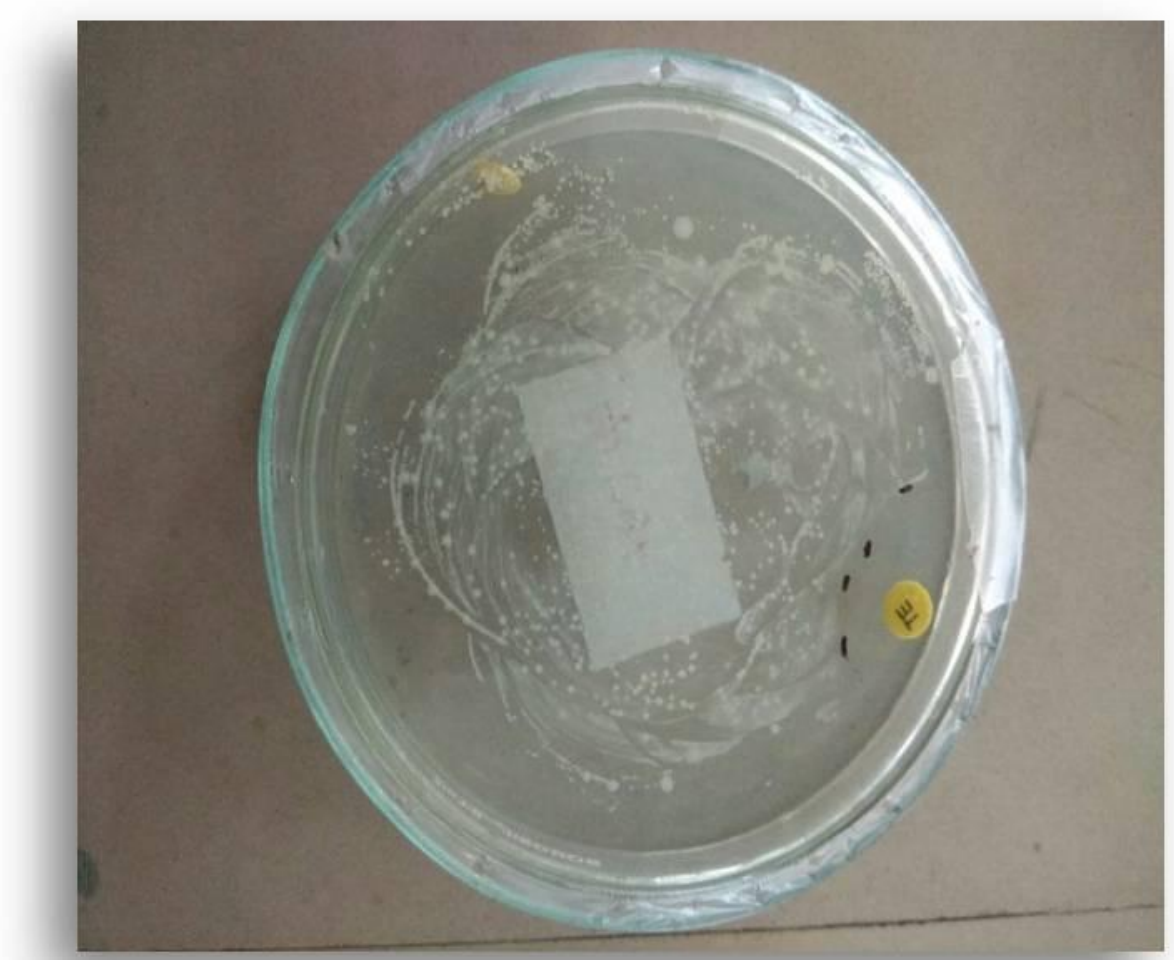

Fig.1

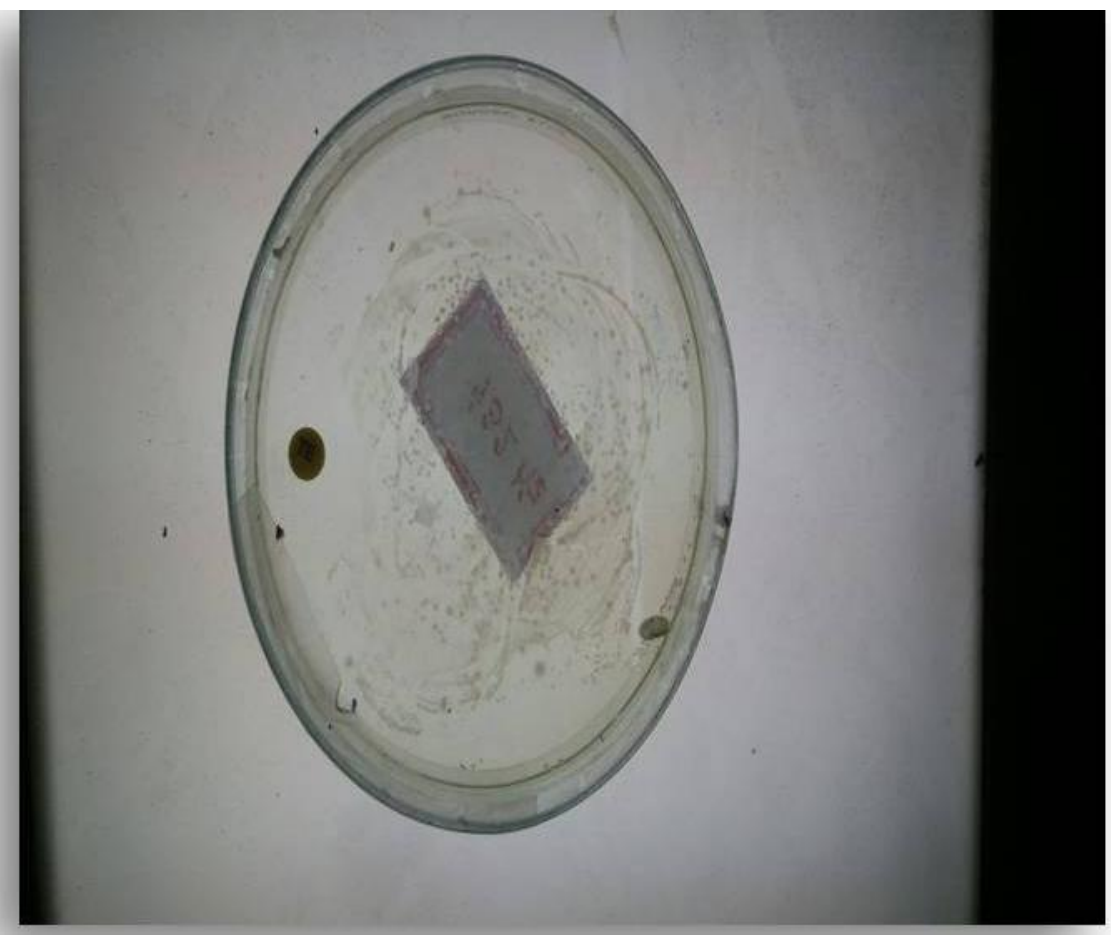

Fig.2 
Int.J.Curr.Microbiol.App.Sci (2018) 7(3): 1931-1939

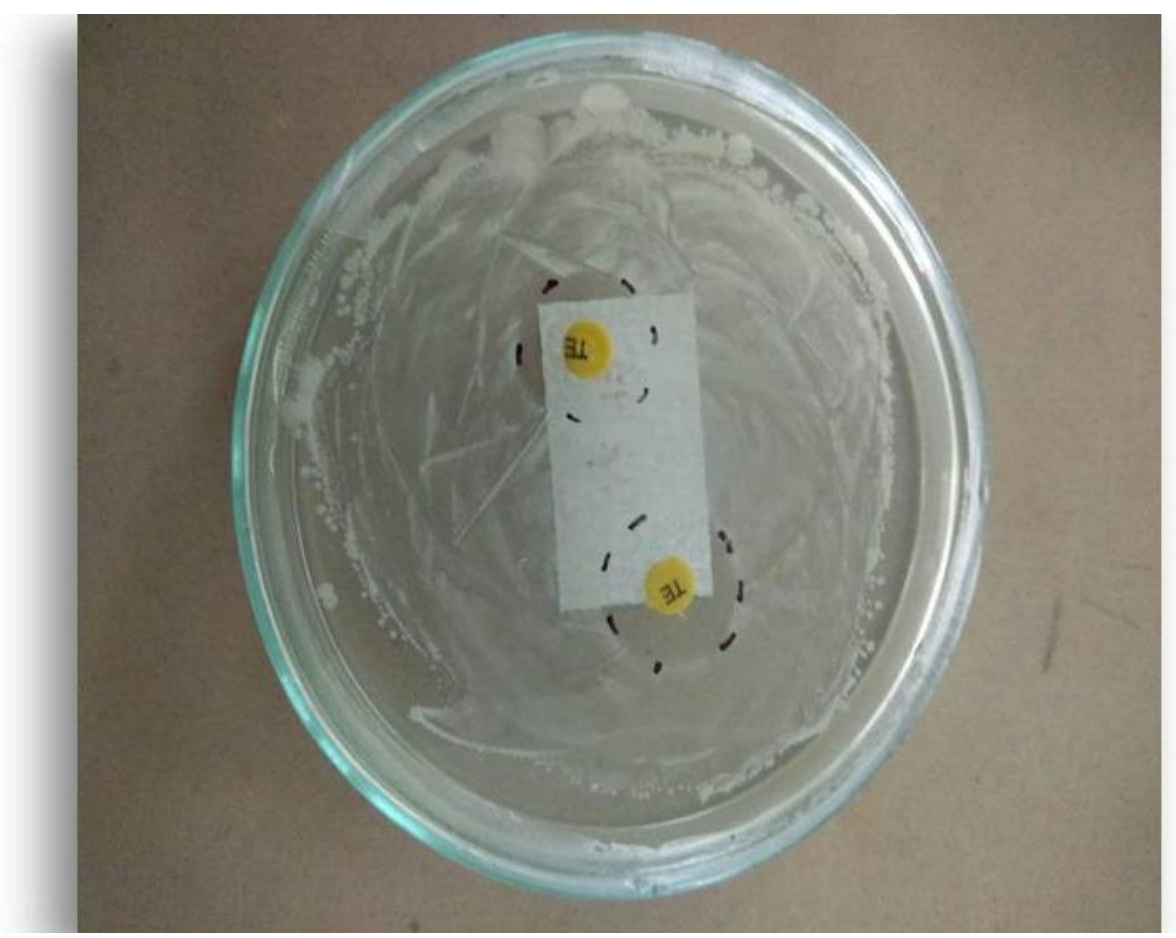

Fig.3

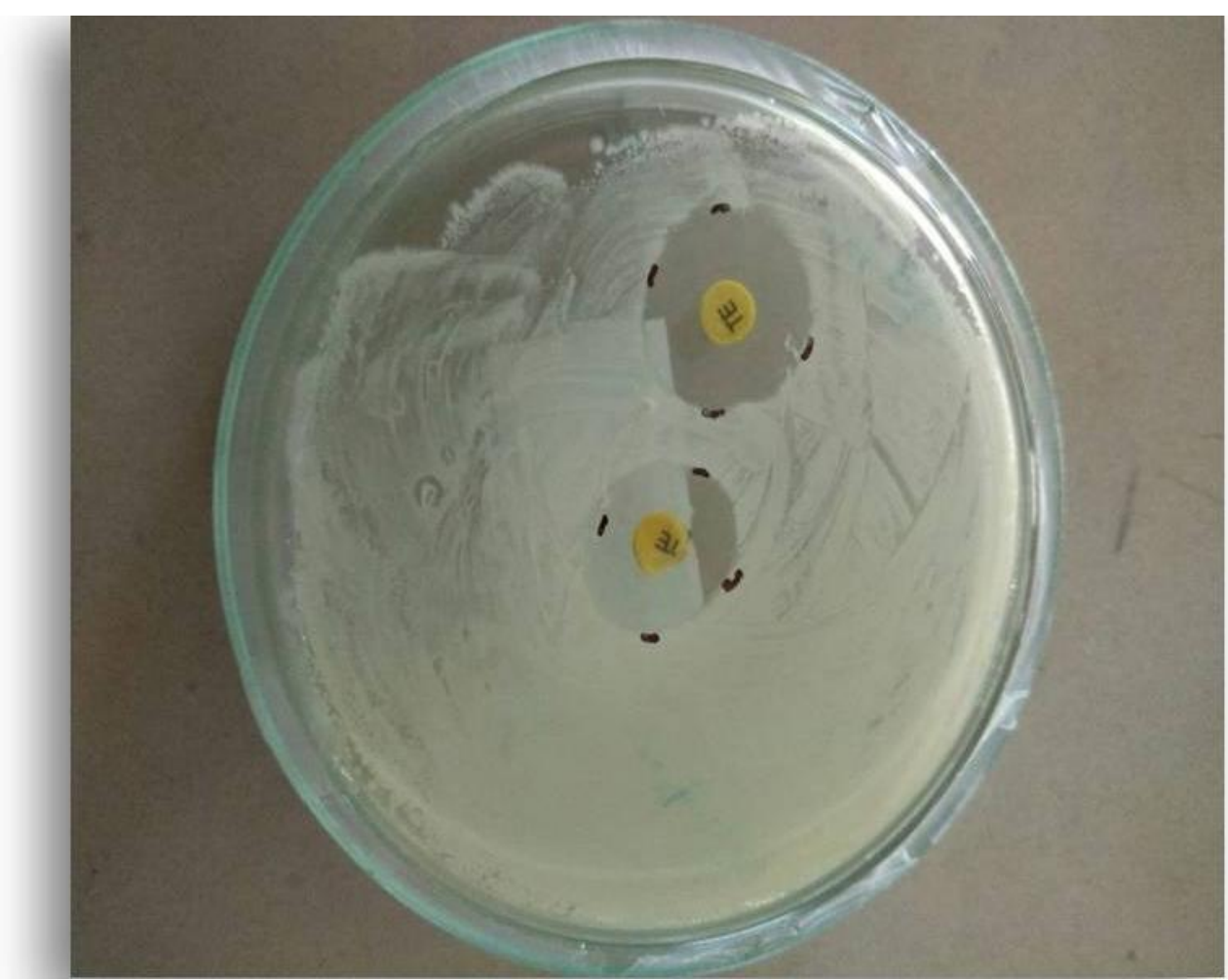

Fig.4

1934 
Int.J.Curr.Microbiol.App.Sci (2018) 7(3): 1931-1939

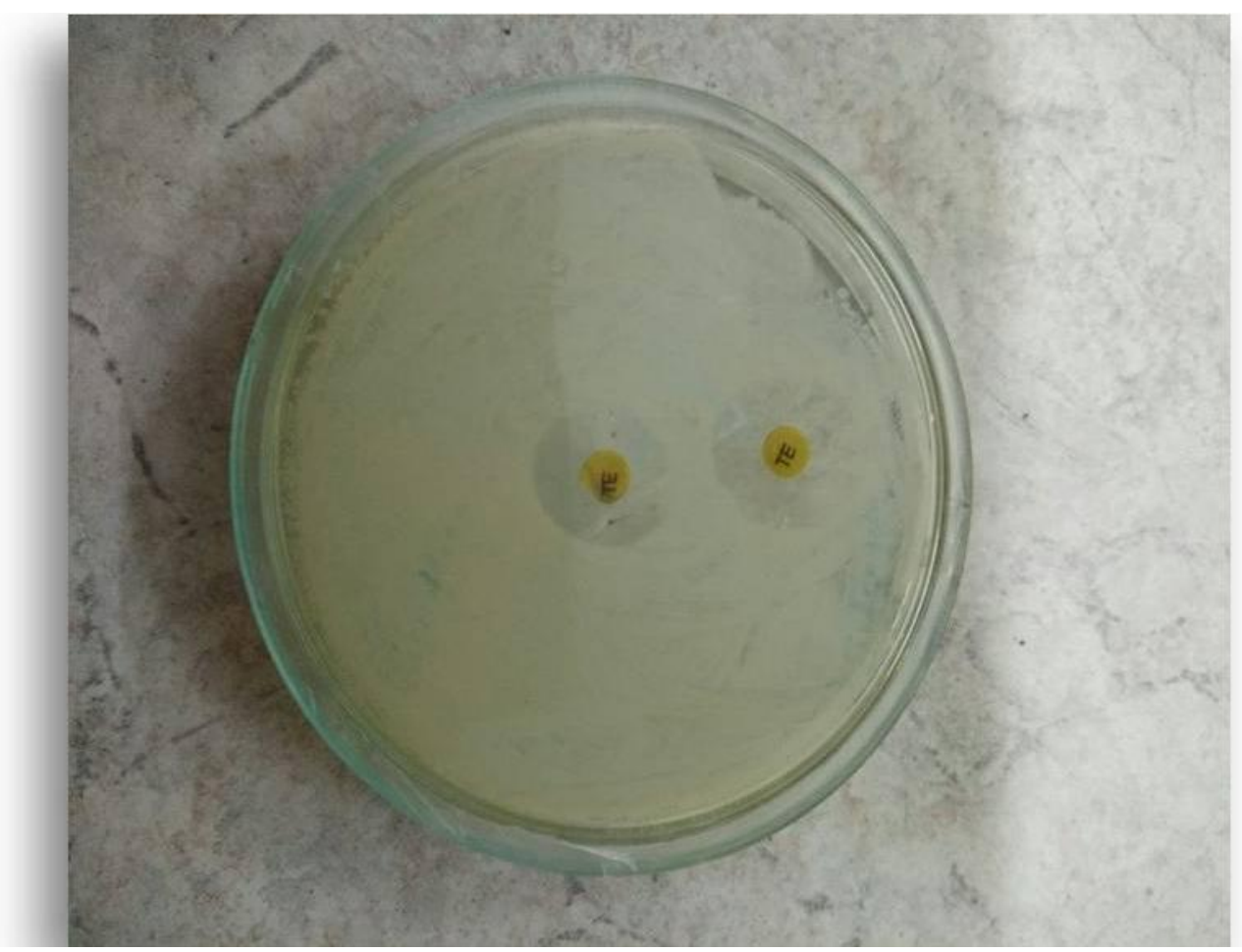

Fig.5

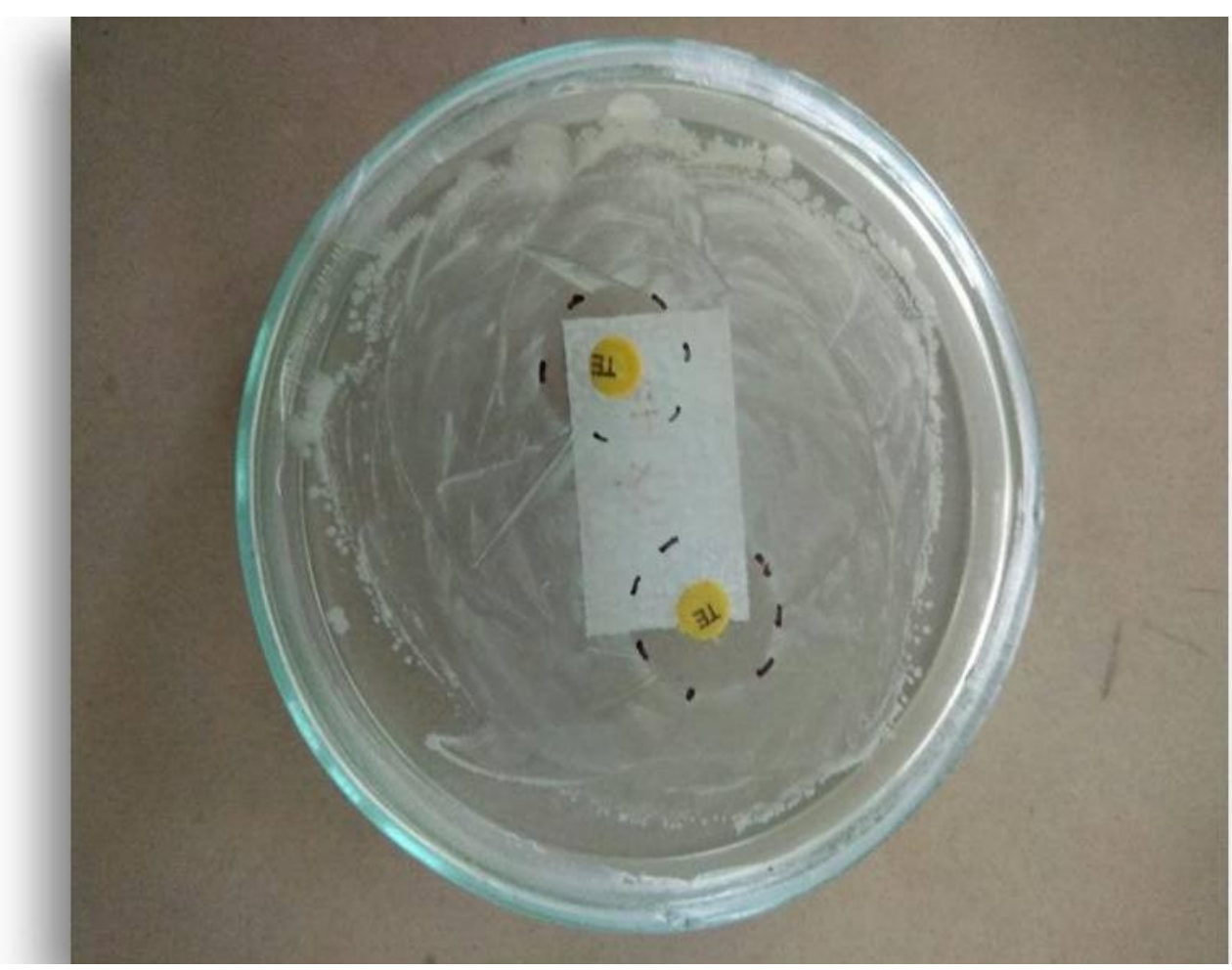

Fig.6 
Table.1 Effect of sound on bacterial growth

Plates under Observation

Control Plate

Plate under $432 \mathrm{~Hz}$

Plate under $4 \mathrm{KHz}$
No. Of Colonies

39 (9 big and 30 small)

46 ( 8 big and 38 small)

06 (2 big and 4 small)

Table.2 Effect of sound on antibiotic susceptibility

Plates under Observation

Control Plate

Plate under $432 \mathrm{~Hz}$

Plate under $4 \mathrm{KHz}$

The accumulation of these species leads to the oxidative damage of the cells, adding to which, there are several other damages caused. In general, harmful effects of these species on the cell are most often which are of the form of:-

\section{Damage of DNA or RNA.}

\section{Lipid Peroxidation.}

\section{Oxidation of Amino acids in proteins}

Oxidative deactivation of specific enzymes by oxidation of co-factors

The bacterial cell membranes consist of a large numbers of Mechanosensitive Channels which are actually the proteins that opens a conductance pore in response to any sort of mechanical stress. MS Channels have been implicated in touch, hearing, cardiovascular regulations etc. The function of these Mechanosensitive channels is mainly to convert any sort of physical vibrations into biological vibrations, such that the cell is not harmed in any way. When we increase the sound frequency above $1 \mathrm{KHz}$, the high frequency sound waves causes to develop an

\section{Zones Of Inhibition}

$18 \mathrm{~mm}$

$20 \mathrm{~mm}$

$17 \mathrm{~mm}$ internal tension that certainly widens these small pores, which as a result leads to the bursting of the cell and hence ends in apoptosis.

\section{Effect of sound on antibiotic susceptibility}

The second set of petri dishes which were used to study the antibiotic susceptibility, were taken out from the incubator after 24 hours of allowed incubation period, and the zones of inhibition were studied in these plates. The control plate which was completely unaffected from any kind of sound interference, was shown to have a zone of inhibition of $18 \mathrm{~mm}$. Contrary to this, the plate which was exposed to a sound frequency below $1 \mathrm{KHz}(432 \mathrm{~Hz})$ was shown to have a zone of inhibition of $20 \mathrm{~mm}$ (Fig.1-6). This certainly demonstrates that, we have an increased antibiotic susceptibility at a frequency of about $432 \mathrm{~Hz}$, which generally refers to the frequency range of any classical music.

On the other side, when we observe the third plate, which was exposed to a sound frequency above $1 \mathrm{KHz}(4 \mathrm{KHz})$ was shown 
to have comparatively a lesser zone of inhibition, that of only $17 \mathrm{~mm}$. This again proves that at a high frequency our test organism is shown to have a decreased antibiotic susceptibility, although by a feeble margin of $5.67 \%$. The consistent repetition of the experiment shows that, at a high frequency such as $4 \mathrm{KHz}$, certain bacteria including our test organism tentatively develops some resistance against the normal dosage of antibiotics, or is no longer susceptible to the antibiotics as they were under low frequencies, i.e. somewhere their extent of susceptibility has decreased.

This experiment clearly aims at a comparative study for the growth and response towards antibiotics of our test organisms and other mesophiles, which generally grows around the human systems under the influence of two largely different values of frequencies. The results were convincing enough to draw a conclusion.

The present study witnessed that test organism to exhibit higher growth at $432 \mathrm{~Hz}$ than without sound, whereas at $4 \mathrm{KHz}$ the case was just reversed. At the same time, we also witnessed our test organism getting more susceptible against antibiotics at $432 \mathrm{~Hz}$ than without sound, whereas at $4 \mathrm{~Hz}$, it seemed to have developed some resistance against the applied antibiotic.

Our body is entirely made up of microorganisms, among which the useful ones constitute our body micro flora, whereas the group of pathogens always tries to cause harm to our body systems. When we get prone to these high frequency sounds in our daily life, we are at a stake of danger from two ways. The first of the two being the lack of growth of our body micro flora under the influence of such high frequency sound waves. The second being the gradual development of the resistance against antibiotics for the pathogens. Together they can make us vulnerable to various diseases. Hence we should always try to keep ourselves away from such high frequency sources.

\section{References}

Berry, R. M., Turner, L., and Berg, H.C., Mechanical limits of bacterial flagellar motors probed by electrorotation, Biophysical. J., 1995, vol. 69, pp. 280286. doi:10.1016/S0006-3495(95)799 00-3

Braam, J. In touch: plant responses to mechanical stimuli, New Physiol., 2005, vol. 165, pp. 373-389. doi: 10.1111/j.1469-8137.2004.01263.x

Choo, J. H., Rukayadi, Y., and Hwang, J.K., Inhibition of bacterial quorum sensing by vanilla extract, Lett. Appl. Microbiol., 2006, vol. 42, no. 6, pp. 637-641. doi:10.1111/j.1472765X.2006.01928.X

Hou, T.Z., Luan, J.Y., Wang, J.Y., and Li, M.Y., Experimental evidence of a plant meridian system: III. The sound characteristics of Phylodendron (Alocasia) and effects of acupuncture on those properties, Am. J. Chin. Med., 1992, vol. 22, pp. 205-214. doi:10.1142/S0192415X94000267

Martinac, B., Mechanosensitive ion channels: an evolutionary and scientific tour de force in mechanobiology, Channels, 2012, vol. 6, no. 4, p. 211. doi:10.4161/ chan. 22047

Matsuhashi, M., Pankrushina, A.N., Takeuchi, S., Ohshima, H., Miyoi, H., Endoh, K., and Sawada, T., Production of sound waves by bacterial cells and the response of bacterial cells to sound, J. Gen. Appl. Microbiol., 1998, vol. 44,1, pp. 49-55. doi:10.2323/jgam. 44.49

Murillo, J.A., Lemus, J.M., and García, L.F., Simultaneous determination of 7- 
aminocephalosporanic acid and 7aminodesacetoxycephalosporanic acid by second derivative spectrophotometry, Anal. Lett., 1991, 24(4): 683-699. doi: 10.1080/00032 719108052935

Nikaido, H., Molecular basis of bacterial outer membrane permeability revisited, Microbiol. Mol. Biol. Rev., 2003, vol. 67(4): 593-65. doi: 10.1128/MMBR. 67.4.593-656.2003

Norris, V. and Hyland, G.J., Do bacteria sing? Sonic intercellular communication between bacteria may reflect electromagnetic intracellular communication involving coherent collective vibrational modes that could integrate enzyme activities and gene expression, Mol. Microbiol., 1997, vol. 24, no. 4, pp. 879-880. doi:10.1046/j.1365-2958.1997.3951756

Pornpongmetta, S. and Thanuttamavong, M., Effects of music on microbial substrate utilization of aerobic bacteria from municipal wastewater treatment plant part II: Comparative effects of musical characteristics, 2010. doi:10.1128/ AEM. 02348-07

Reguera, G., When microbial conversations get physical, Trends Microbiol., 2011, vol. 19, no. 3, pp. 105113.doi:10.1016/j.tim.2010.12.007

Sarvaiya, N. and Kothari, V, Effect of audible sound in form of music on microbial growth and production of certain important metabolites (2015), Volume 84(2): 227-235, 84:227. doi:10.1134/ S0026261715020125

Shaobin, G., Wu, Y., Li, K., Li, S., Ma, S., Wang, Q., and Wang, R., A pilot study of the effect of audible sound on the growth of Escherichia coli, Colloids and Surfaces B: Biointerfaces, 2010, vol. 78, no. 2, pp. 367371.doi:10.1016/j.colsurfb.2010.02.028
Stern, J. and Lewis, W.H.P., The colorimetric estimation of calcium in serum with $\mathrm{O}$ cresolphthalein complexone, Clin. Chim. Acta, 1957, vol. 2, no. 6, pp. 576-580.doi:10.1016/00098981(57)90063-3

Suryawanshi, R.K., Patil, C.D., Borase, H.P. et al., Appl. Biochem. Biotechnol., (2014) 173: 1209. doi:10.1007/s12010014-0921-3

Walley, J.W. and Dehesh, K., Molecular mechanisms regulating rapid stress signaling network in Arabidopsis, J. Integrative Plant Biol., 2010, vol. 52, no. 4, pp. 354-359. doi: $10.1111 /$ j. 17447909.2010.00940.x

Wang, B., Zhao, H., Wang, X., Duan, C., Wang, D., and Sakanishi, A., Influence of sound stimulation on plasma membrane H+-ATPase activity, Colloids and Surfaces B: Biointerfaces, 2002, vol. 25, no. 3, pp. 183-188. doi:10.1016/S0927-7765(01)00320-4

Xiujuan, W., Bochu, W., Yi, J., Chuanren, D., and Sakanishi, A., Effect of sound wave on the synthesis of nucleic acid and protein in Chrysanthemum, Colloids and Surfaces B: Biointerfaces, 2003, vol. 29, no. 2, pp. 99-102.doi:10. 1016/S0927-7765(02)00152-2

Ying, J.C.., Dayou, J., and Phin, C.K., Experimental investigation on the effects of audible sound to the growth of Escherichia coli, Modern Appl. Sci., 2009, vol. 3, no. 3, p. 124. doi:10.5539/mas.v3n3p124

Yoshimura, M. et al., "Sound wave" signals, emitted by bacteria and yeast cells, regulate the propagation of yeast under alcohol stress, Japan Soc. Biosci., Biotechnol. Agrochem., Aug. 1, 1995, Conference Abstracts. doi:10.1134/S00 26261715020125. 


\section{How to cite this article:}

Souvik Banerjee, Abhishek Goswami, Ananya Datta, Anish Pyne, Anjoom Nikhat and Bodhisattwa Ghosh. 2018. Effect of Different Sound Frequencies on the Growth and Antibiotic Susceptibility of Escherichia coli. Int.J.Curr.Microbiol.App.Sci. 7(03): 1931-1939. doi: https://doi.org/10.20546/ijcmas.2018.703.229 